\title{
Graphitization in Low Alloy Steel Pressure Vessels and Piping
}

\author{
Iván Uribe Pérez • Tito Luiz da Silveira • \\ Tito Fernando da Silveira $\cdot$ Heloisa Cunha Furtado
}

Submitted: 12 November 2010/Published online: 2 December 2010

(C) ASM International 2010

\begin{abstract}
This article discusses the problem of graphitization that can occur in carbon steels exposed to high temperature for extended time when these are present in pressure vessels and piping. Several case studies are described dealing with actual failures that have been investigated by the authors.
\end{abstract}

Keywords Graphite - Carbon steel ·

Pressure vessels and piping · Metallography .

Planar distribution of graphite nodules · Structural integrity

\section{Introduction}

The formation of graphite nodules can occur in carbon and low alloy steels used in pressure vessels and piping when exposed to high temperature for extended time. When such formation takes place, the nodules may have a random distribution or form a planar array within the microstructure. Planar arrays are more commonly found in the heataffected zone (HAZ) at a weld, in which case, the region can be severely embrittled, whereas dispersed nodules may cause a mild loss of strength.

Carbon steels used at high temperature for pressure vessels and piping typically have a microstructure of ferrite

\section{U. Pérez}

Universidad Industrial Santander, Grupo de Investigaciones en

Corrosión, Bucaramanga, Colombia

T. L. da Silveira - T. F. da Silveira

TSEC Integridade Estrutural Ltda, Rio de Janeiro, Brazil

H. C. Furtado $(\square)$

Electric Energy Research Center, DTE, Rio de Janeiro, Brazil

e-mail: heloisa@cepel.br and pearlite, and with extended exposure to temperature, the pearlite decomposes to form a dispersion of carbides in a ferrite matrix. Similar effects occur in carbon-molybdenum and carbon-chromium-molybdenum steels in which the carbides formed have a composition $\mathrm{M}_{x} \mathrm{C}_{y}$. Over-aging promotes the coalescence of the small carbides formed from the pearlite decomposition and prolonged aging leads to a structure of ferrite with an almost uniform distribution of spheroidized carbides. This occurs after prolonged exposure to temperatures in excess of $400{ }^{\circ} \mathrm{C}$ for carbon steels, and of around $420^{\circ} \mathrm{C}$ for low alloy steels.

Graphitization is a reaction that is observed in some steels in which the carbides dissociate to form graphite nodules and ferrite when subjected to prolonged exposure to temperatures of around $430{ }^{\circ} \mathrm{C}$ or above. Despite the favorable thermodynamic driving force, the reaction is rarely observed in modern steels as the kinetics of the transformation are slow, and steels containing over $0.7 \%$ $\mathrm{Cr}$ by weight are considered immune to this reaction.

The spheroidization and graphitization reactions coexist over a range of temperature. In Fig. 1(a), graphite has nucleated within a matrix old ferrite and pearlite, while in Fig. 1(b), the entire pearlite has disappeared and the entire cementite has dissociated so that the structure consists of graphite nodules in ferrite. The graphitization reaction is represented schematically in Fig. 2 which also shows how the reaction is accelerated with increase in temperature.

\section{Nucleation and Growth of Graphite}

The nucleation of graphite nodules demands mobility of carbon atoms available from the dissolution of pre-existing carbides having compositions of the form $\mathrm{M}_{x} \mathrm{C}_{y}$. As with any reaction depending on diffusion, the temperature to 
Fig. 1 A graphitized medium carbon steel; (a) graphite nodule in pearlite, with uniform distribution of cementite particles in pearlite around it; (b) same steel overagedcomplete graphitization and phases present are ferrite and graphite only

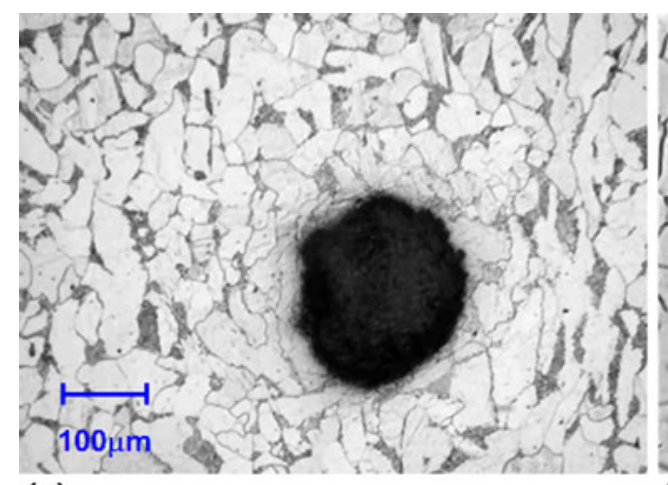

(a)

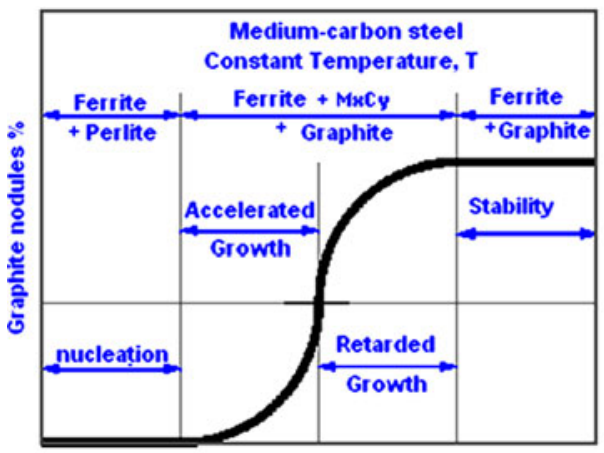

Log Time ( Constant Temperature, $\mathrm{T}$ )

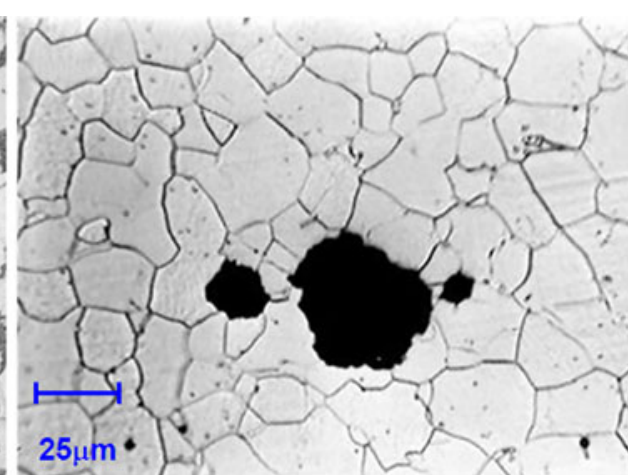

(b)
Fig. 2 Stages of graphitization of a medium carbon steel aged at constant temperature, showing the effect of temperature during aging

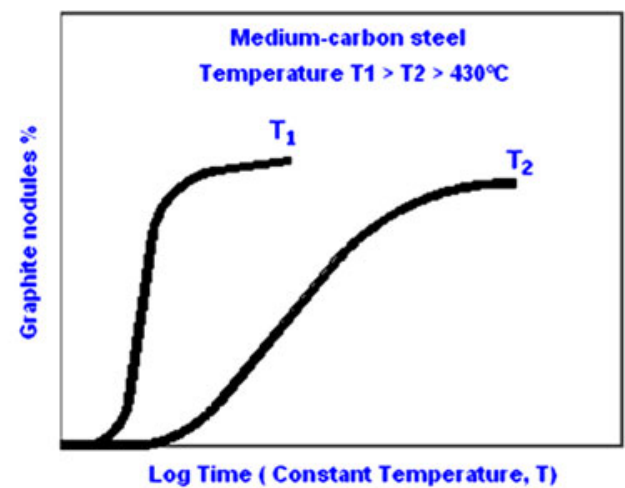

which the material is exposed is a determining factor in the rate of the process.

In the 1950s, the presence of graphitization was confirmed in $33.8 \%$ of 554 samples removed from pressure vessels and piping operating at high temperature [1]. The study made at that time associated statistically the presence of aluminum to the graphitization [2]. Although the literature may present contradictions [3], the presence of aluminum alone or in combination with other elements is certainly a strong factor favoring this relation. Not only aluminum, but also silicon and nitrogen among other factors, are referenced in the literature as agents capable of affecting the graphitization process [4]. The alloying elements present can influence graphitization in different ways: by affecting the stability of the $\mathrm{M}_{x} \mathrm{C}_{y}$ carbides; by interfering with the diffusion of the carbon in the matrix; or by acting as preferential sites for nucleation.

The temperature and the stoichiometric of the carbide composition are the variables that control the nucleation of graphite nodules in the matrix ferrite. However, these two variables, by themselves, are insufficient to explain the graphite nucleation in the form of planar arrays in the HAZs of welds that is observed in practice and will be shown subsequently.

It has been suggested that there is a contribution to the susceptibility of graphitization in different types of steel from hardness produced by plastic strain [5, 6], and it is reasonable to believe that the thermal stresses of welding will impose a varying degree gradient of plastic deformation on the base metal.

After nucleation, it is expected that the fraction of graphite present will grow rapidly, as illustrated in Fig. 2. Foulds et al. [7] proposed an empirical relationship between the fraction of carbon $(\varnothing)$ in the graphite and continuous service time $t$, after the nucleation step, and considered an Arrhenius type relationship to represent the thermally activated effect of absolute temperature $T$ on the diffusion of carbon atoms.

\section{Industrial Cases}

\section{Case 1: Welded Joint in a Superheated Steam Tube}

The case involved a steam transfer line that had to be replaced after failure at the junction between the straight and curved sections at the inner radius. Failure occurred by wall creep at the inner radius of the pipe. The material was seamless carbon steel (DIN 1.0305 ST 35.8) of nominal composition (wt.\%): 0.17 max C, $0.10-0.35 \mathrm{Si}, 0.4-0 \mathrm{Mn}$, $0.04 \max \mathrm{P}$, and $0.04 \max \mathrm{S}$. The design specification was $42 \mathrm{kgf} / \mathrm{cm}^{2}$ pressure, wall temperature $400{ }^{\circ} \mathrm{C}$. 
The dimensions were: O.D. $168 \mathrm{~mm}$, thickness $7.4 \mathrm{~mm}$, and operating time $290,000 \mathrm{~h}$.

Figure 3 shows a neighboring section of the pipe that was analyzed, with the section removed for detailed examination conducted at the junction between the straight and curved sections of the pipe.

The detailed examination was made of the specimen at the weld between the straight and curved sections of the pipe. It is apparent that there is extensive graphite nodule

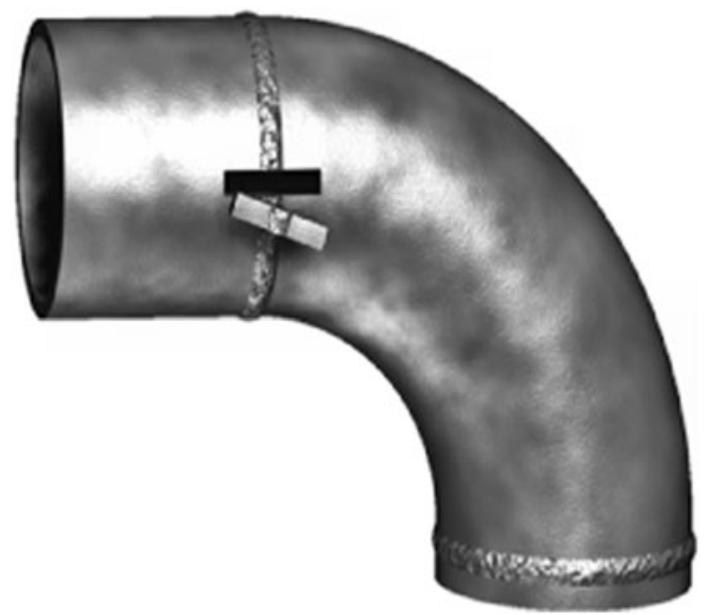

Fig. 3 The curved section of pipe analyzed formation in the curved portion of the pipe as may be seen in the views labeled $4 \mathrm{C}, 4 \mathrm{D}, 4 \mathrm{~N}$, and $4 \mathrm{~L}$, whereas in the straight portion of the pipe, the pearlite has not dissociated to any significant extent (Fig. 4).

Case 2: Longitudinal Welded Joint of Distillation Tower of Catalytic Cracking Unit

The tower was constructed of ASTM A285 Gr. C carbon steel, with an internal liner of AISI 410 stainless steel, and designed in conformity with ASME Section VIII, Division 1 of the ASME Boiler and Pressure Vessel Code. The wall temperature was $432{ }^{\circ} \mathrm{C}$, and the operating time was $240,000 \mathrm{~h}$.

The lower third of the tower was replaced as a result of excessive diametral expansion from creep.

Figure 5 illustrates the results of the metallographic examination.

In the base metal illustrated in areas $5 \mathrm{~A}$ and $5 \mathrm{~B}$ of Fig. 5, the ferrite grains contain coalesced carbides as well as a random distribution of graphite nodules. At the weld shown in area $5 \mathrm{C}$, there is a planar arrangement of graphite nodules within the wall over the segment marked as L. The nodules do not reach the surfaces of the plate and could not therefore be detected by normal nondestructive surface examination techniques.

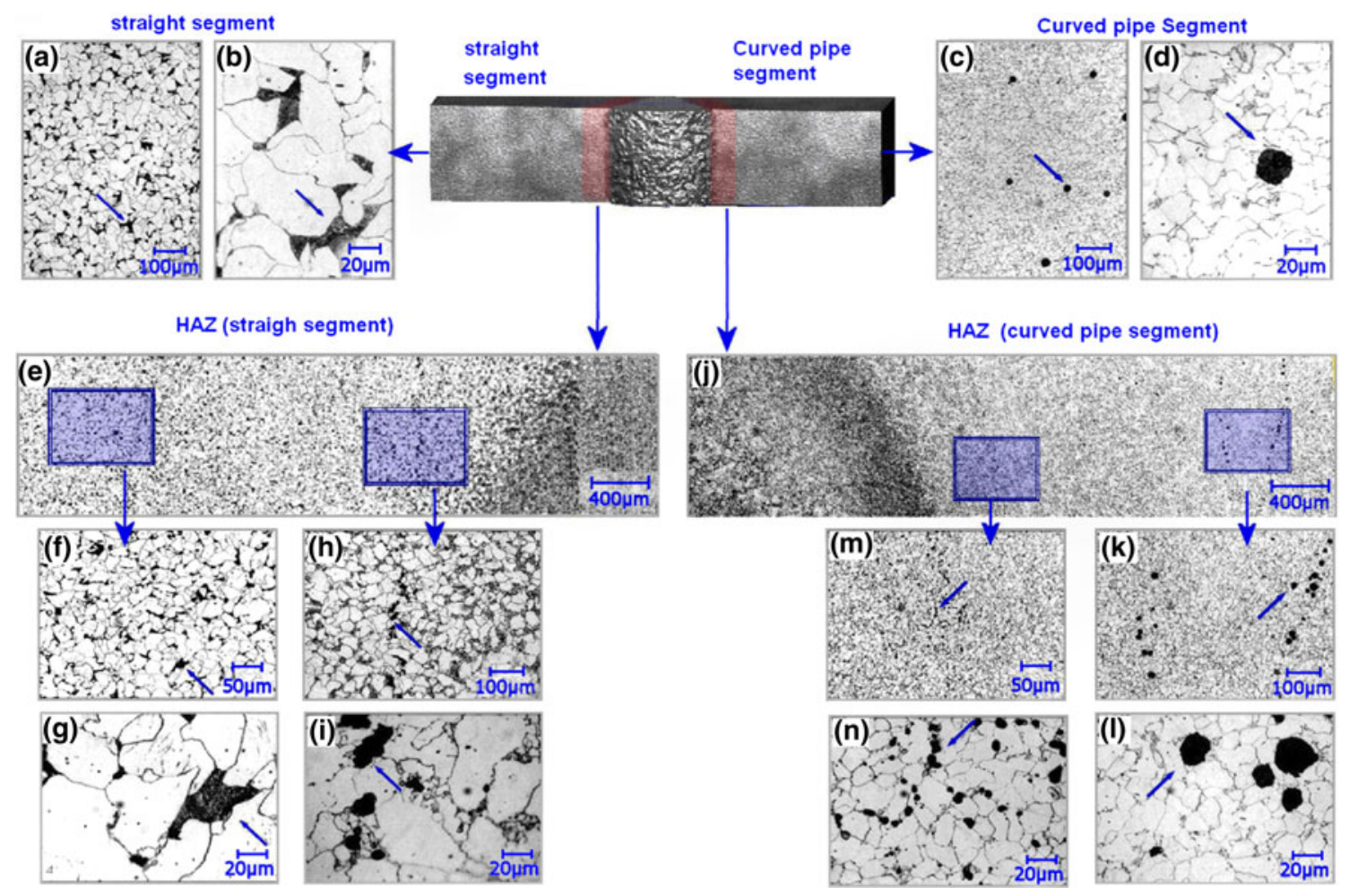

Fig. 4 Details of the metallographic examination of the specimen cut from the curved tube shown in Fig. 3 


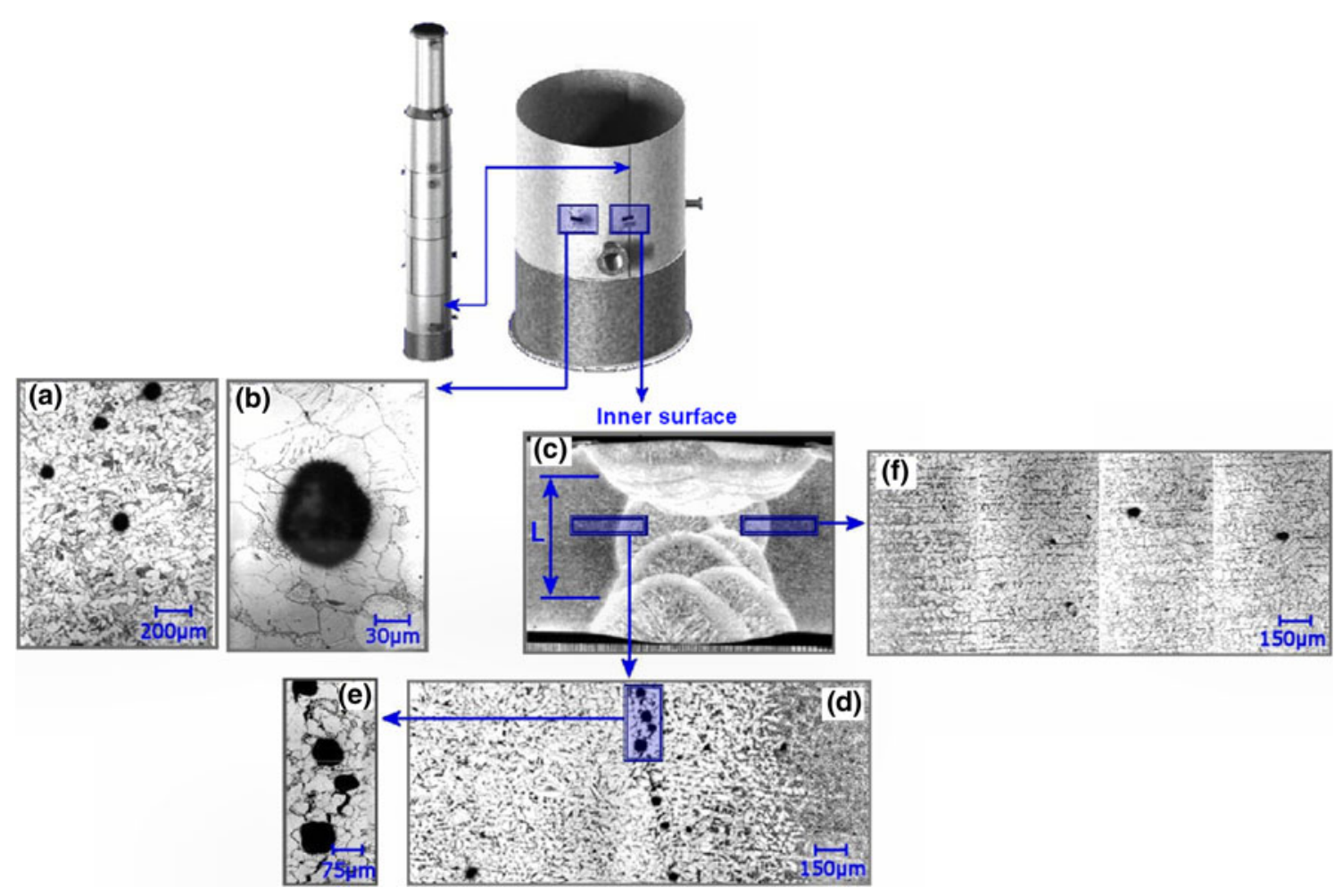

Fig. 5 Metallographic examination of the carbon steel of the base metal and heat-affected zone on both sides of the longitudinally welded plate of the inferior ring of the reactor

It may be noted that the graphite nodules at the weld, acting in conjunction with the principal tensile stress, have initiated microcracks shown in area 5E.

The planar arrangement of graphite nodules on one side of the weld in the plate constituting the ring, as shown in $5 \mathrm{D}$, contrasts with the absence of such nodules on the other side of the weld, and this emphasizes the unpredictability of the material behavior in terms of graphitization.

\section{Case 3: Water Wall of Steam Boiler}

A region of the water wall tubes of a boiler was overheated because of the incidence of flames. This occurred in the vicinity of the burners. The result was severe oxidation, local deformation with diametral expansion, and cracks from corrosion fatigue. One of the tubes containing a small hole was analyzed; the sequence of the examination conducted is presented in Fig. 6.

The tube was of ASTM A210 Grade A1 carbon steel, and it has been in service for $210,000 \mathrm{~h}$.

Areas $6 \mathrm{E}$ and $6 \mathrm{~F}$ of Fig. 6 show randomly distributed graphite nodules as well as others in a planar arrangement. Area $6 \mathrm{G}$ shows that two sets of oriented planes of graphite nodules are apparent, lying approximately at right angles to each other, while the aligned nodules shown in Area $6 \mathrm{D}$ lie parallel to the edge of the perforation, suggesting that the rupture was aided by the aligned graphite nodules.
Such failures occurring along planes on which graphite nodules have formed have been reported previously by Furtado and Le May [8].

\section{Discussion}

Graphitization is a reaction which has long been known. According to Wilson [1], one case of graphitization in tubes of a thermal cracking furnace in an oil refinery was reported in the United States in 1935. The incident aroused no interest, as the graphite nodules had a random distribution, and the analysis showed that there was no risk to the structural integrity of the equipment. According to this author, in 1943, a steam transfer line at a US power generating station failed during service: the pipe had been operating for $48,000 \mathrm{~h}$ at $500{ }^{\circ} \mathrm{C}$, and the failure resulted because of a planar arrangement of graphite nodules running through the HAZ of a welded joint. This accident led to an extensive research program focused on the thermal power generation industry.

In 1951, three catalytic cracking reactors in oil refineries of the United States failed over a short period of time. The root cause of these accidents was initially attributed to graphitization, and so the oil refining industry had to further study and improve its knowledge about the problem. The collective effort resulted in a reduction in the risk of 

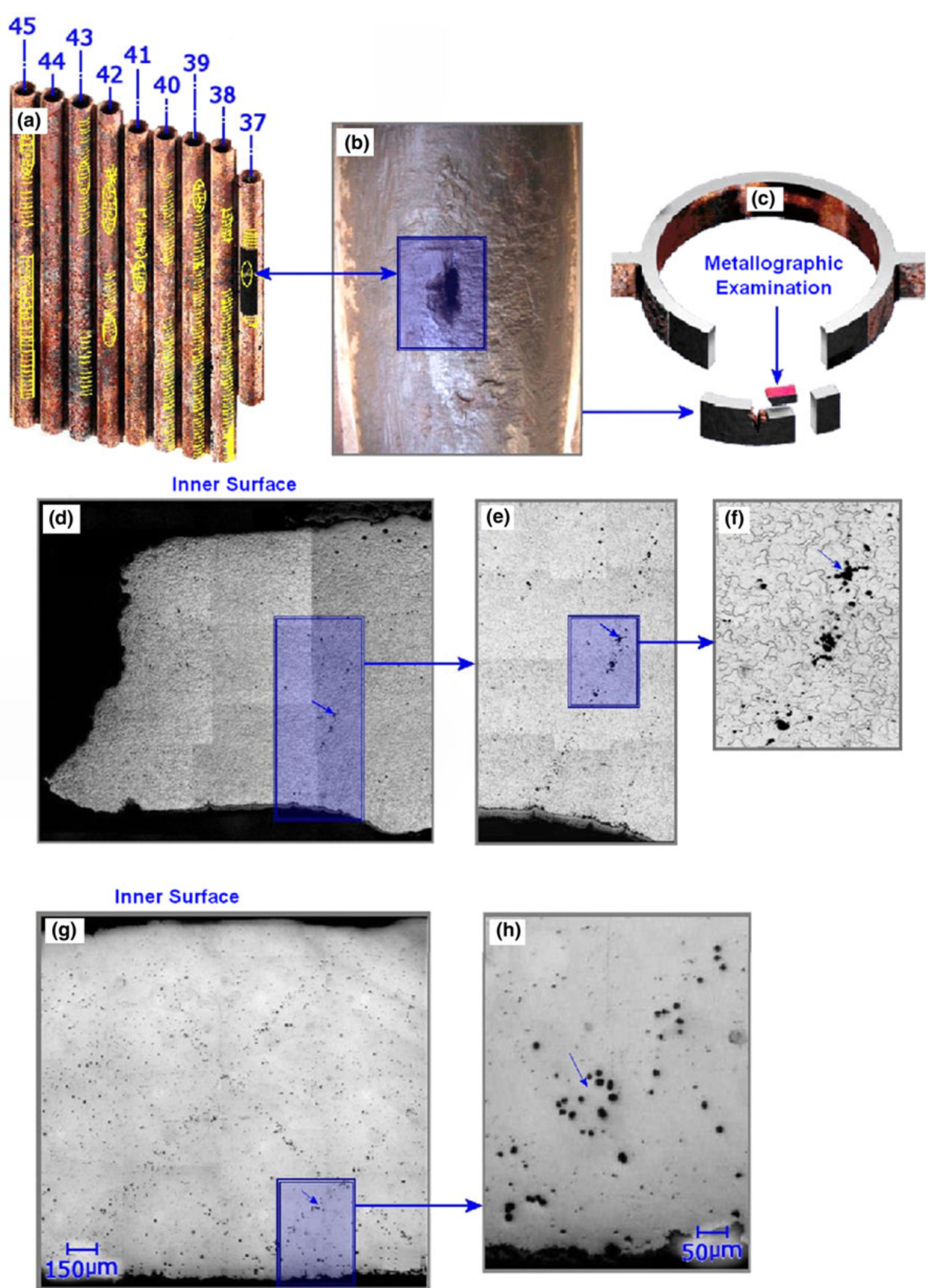

Fig. 6 Examination sequence of water wall tube that had suffered overheating and consequent perforation

failure by graphitization in subsequently designed equipment, although the nature of the mechanism of graphitization remained unclear.
This progress was made by improving the quality of steels prone to graphitization, especially by limiting the content of aluminum, with a reduction in maximum operating 
temperature. Temperature reduction was obtained in two ways: one was the improving of weldability of steels having $\mathrm{Cr}$ levels above $1 \%$, thus replacing steels susceptible to graphitization in equipment exposed to temperature above which graphitization occurs. The other was the development of refractory compatible with the application on the inner surfaces of pressure vessels and piping. The substantial reduction in cases of graphitization caused a decreasing interest in this failure mechanism in the 1970s and 1980s with regard to high-temperature structural applications.

From the 1990s, there has been a renaissance of interest in graphitization, which is attributed not only to increased failure probability but also to the severity of the consequences should they occur, and the public aversion against risks to physical safety and the environment. The API Recommended Practice RP-571 presents the modern view of graphitization in technological aspect [3].

Cases 2 and 3, detailed in this article are typical examples among many others in the literature, which illustrate a loss of structural integrity promoted by graphitization. The treatment to be applied to graphitization, in relation to the structural integrity of pressure vessels and piping, requires consideration of the prediction of its severity and the consequences resulting from it, and the tests required to characterize it.

Regarding prediction, not all carbon and carbonmolybdenum steels for structural applications get graphitized when exposed for a long time at temperatures above $430{ }^{\circ} \mathrm{C}$. The reasons for the resistance of these steels to graphitization are not well established. When pearlite of the typical original microstructure decomposes to form graphite nodules, they may not take the form of planar arrays, but may have a random distribution.

The cause of planar arrangements of graphite nodules in steels is uncertain. The requirements for their presence are a combination of factors that determine the formation of planar arrays in welded joints and are well illustrated in Cases 1 and 2. In the Case 1, there is a planar arrangement near the weld joint, (see area $4 \mathrm{H}$ ), although the base metal very close to this joint does not even provide significant evidence of pearlite decomposition in areas $4 \mathrm{~B}$ and $4 \mathrm{G}$.

In the Case 2, the planar arrangement of graphite nodules is seen only at one side of a welded joint of a ring of a carbon steel sheet. What led to such a preference for the particular location of the planar arrangement remains unknown. Temperature and service time are the same on both sides of the weld. Thus, planar nucleation must have resulted from a combination between several variables associated with the stoichiometry of the base metal and the welding process.

Regarding Case 3, several metallographic samples were taken from the panel of tubes in the water wall shown in Fig. 6. Other samples, from similar locations were also analyzed. Planar arrangements documented in areas $6 \mathrm{E}$ and $6 \mathrm{G}$ occupy a relatively small fraction of the area where the graphitization occurs in the form of a random distribution of nodules.

The three cases discussed show that knowledge is incomplete concerning the mechanism of graphitization, which prevents prediction of its occurrence. Since it is not possible to anticipate the behavior of graphitization in equipment exposed to conditions that favor this reaction, it is only evidence of their activity to verify and classify the severity of the results through appropriate inspection.

As regards the severity of graphitization, a study conducted in 1935 in a tube furnace containing a random pattern of nodules concluded that there was significant loss of structural integrity [1], and there is agreement even today with this view [3,9-11]. Damage can be considered as some change affecting the fitness for service of equipment, and it is important to recognize that the graphitization in the form of a random distribution of nodules need not be considered as damage if it does not affect safety.

Loss of structural integrity due to the graphitization takes place when the nodules are arranged in planar arrays. In this case, the severity of graphitization is much larger if the planar arrangement is normal to the orientation of the principal tensile stress. This condition was present in Case 2, where the planar arrangement accompanied a welded joint subjected to tension. In Case 1, the planar arrays were oriented in the same direction as the principal tensile stress, so that there was no relation with the nodules, even though they were very close to each other; see areas $4 \mathrm{~K}$ and $4 \mathrm{~L}$.

\section{Conclusions}

In summary, the article demonstrates through three cases of failure in service the unpredictability of the material behavior on graphitization, and discusses implications of this reaction on the structural integrity of pressure vessels and pipes. Despite the fact that the graphitization reaction has been studied for several decades, the exact cause of the formation of planar arrays of graphite nodules remains unknown.

\section{References}

1. Wilson, J.G.: Graphitization of steel in petroleum refining equipment. In: 20th Midyear Meeting of the American Petroleum Institute, Division of Refining, St. Louis, USA (1955)

2. Hall, A.M.: Graphite formation in petroleum-refining equipment. In: Proceedings of the Forth World Petroleum Congress, Section VII.C; Paper 2, pp. 213-226. Rome, Italy (1955)

3. Damage Mechanisms Affecting Fixed Equipment in the Refining Industry, Recommended Practice API RP-571, pp. 4.1-4.7. American Petroleum Institute (2003) 
4. Fiorentino, R.J., Hall, A.M., Jackson, J. H.: Effect of certain elements on the graphitization of steel. In: The Annual Meeting of The American Society of Mechanical Engineers, Nov. 1953

5. Baranov, A.A.: Effect of plastic strain on graphitization of steel. Met. Sci. Heat Treat. 3, 17-18 (1961)

6. Neri, M.A., Colás, R., Valtierra, S.: Effect of deformation kinetics in high carbon steels. J. Mater. Process. Technol. 83, 142-150 (1998)

7. Foulds, J.R., Viswanatham, R.: Graphitization of steels in elevated-temperature service. J. Mater. Eng. Perform. 10(4), 484-492 (2001)
8. Furtado, H.C., Le May, I.: Evaluation of an unusual superheated steam pipe failure. Mater. Charact. 49, 431-436 (2003)

9. Metals Handbook, Properties and Selection: Irons, Steels, and High-Performance Alloys, 10th edn., vol. 1, p. 642. ASM International, Materials Park, USA (1990)

10. Thielsch, H.: Defects and Failures in Pressure Vessel and Piping. Rheinhold Publishing Co, New York, USA (1965)

11. Hau, J., Seijas, A., Munsterman, T., Mayorga, A.: Evaluation of Aging Equipment for Continued Service, Corrosion 2005, Paper 05558. NACE International, Houston, USA (2005) 